\title{
Computational Flow Dynamics of the Severe M1 Stenosis Before and After Stenting
}

\author{
Dae Chul Suh, MD, PhD', Young Bae Ko, MS, ${ }^{3,}$ Sung-Tae Park, MD, Kyunghwan Yoon, PhD, \\ Ok Kyun Lim, RT'1, Jin Sun Oh, BS'1, Yun Gyeong Jeong, BS'1, Jong Sung Kim, MD²
}

Purpose: Computational flow dynamic (CFD) study has not been widely applied in intracranial artery stenosis due to requirement of high resolution in identifying the small intracranial artery. We described a process in CFD study applied to symptomatic severe intracranial (M1) stenosis before and after stenting.

Materials and Methods: Reconstructed 3D angiography in STL format was transferred to Magics (Materialise NV, Leuven, Belgium) for smoothing of vessel surface and trimming of branch vessels and to HyperMesh (Altair Engineering Inc., Auckland, New Zealand) for generating tetra volume mesh from triangular surface-meshed 3D angiogram. Computational analysis of blood flow in the blood vessels was performed using the commercial finite element software ADINA Ver 8.5 (ADINA R \& D, Inc., Lebanon, MA). The distribution of wall shear stress (WSS), peak velocity and pressure in a patient was analyzed before and after intracranial stenting.

Results: Computer simulation of wall shear stress, flow velocity and wall pressure before and after stenting could be demonstrated three dimensionally by video mode according to flow vs. time dimension. Such flow model was well correlated with angiographic finding related to maximum degree of stenosis. Change of WSS, peak velocity and pressure at the severe stenosis was demonstrated before and after stenting. There was no WSS after stenting in case without residual stenosis.

Conclusion: Our study revealed that CFD analysis before and after intracranial stenting was feasible despite of limited vessel wall dimension and could reveal change of WSS as well as flow velocity and wall pressure.

Key Words : Cerebral artery; Atherosclerosis; Magnetic resonance imaging (MRI); Plaque rupture; Fluid structure interaction

'Departments of Radiology and Research Institute of Radiology, ${ }^{2}$ Neurology, Asan Medical Center, Seoul, Korea

${ }^{3}$ Department of Mechanical Engreering, Dankook University, Yongin, Korea

${ }^{4}$ Department of Radiology, Soonchunhyang University Hospital, Seoul, Korea

${ }^{5}$ Molding \& Forming Technology Team, KITECH, 7-47, Incheon, Korea

Received December 5, 2010;

accepted after revision January 26, 2011

Correspondence to: Dae Chul Suh, MD, Department of Radiology, University of Ulsan, College of Medicine, Asan Medical Center, 86 Asanbyeongwon-gil, Songpa-gu, Seoul 138-736, Korea.

Tel. 82-2-3010-4366 Fax.82-2-476-0090 E-mail: dcsuh@amc.seoul.kr

Neurointervention $2011 ; 6: 13-16$

This is an Open Access article distributed under the terms of the Creative Commons Attribution Non-Commercial License (http://creativecommons.org/licenses/by-nc/3.0) which permits unrestricted non-commercial use, distribution, and reproduction in any medium, provided the original work is properly cited. 


\section{Dae Chul Suh, et al.}

Because intracranial atherosclerotic stenosis is angiographically more common than extracranial lesions in Koreans, intracranial stenting has been performed more frequently than in Western countries $(1-3)$. Although intracranial angioplasty and/or stenting is believed to be beneficial for patients who are resistant to medical treatment, appropriate indication of intracranial stenting and long term outcome data is still not sufficient (4-6).

Although final luminal diameter after stenting is critical for the patient outcome, hemodynamic factors prone to adverse events or restenosis leading to target vessel revascularization in intracranial artery have not been well demonstrated (4). Few studies of the hemodynamics in small-caliber intracranial vessels have been conducted especially in vessels associated with severe stenosis (5-9). The reason of the difficulties to apply this computational flow dynamics (CFD) research to intracranial artery is in part due to the limited resolution of stenotic lumen imaged by current technologies because resolution of target vessel has precluded the development of a realistic geometry for use in finite element modeling and CFD analysis (10, 11).

We developed a process of CFD technique to elucidate the local hemodynamics as a result of atherosclerosis of the small intracranial arteries before and after intracranial stenting.

\section{MATERIALS AND METHODS}

\section{Three D Reconstruction and Data Transfer}

Three dimentional (3D) rotational angiography was obtained in AXIOM Artis Zee (Siemens, Erlangen, Germany). The 3D angiographic images were transferred to Syngo workstation (version VB 15D) to generate $3 \mathrm{D}$ angiography from which 2 nd reconstruction was performed by reducing FOV and adjusting the target vessel. The final image was transformed to STL format in $256 \times 256$ pixels. Because there was no direct connection between the Syngo workstation and the images were sent to Magic RP (ver. 12. 01, Materialise, Leuven, Belgium) in other workstation for smoothing of vessel surface and trimming of branch vessels. And then the image tranfered to Hypermesh (Altair Engineering, Inc., Auckland, New Zealand) to generate tetra volume mesh from triangular surface-meshed 3D angiogram.

\section{CFD Analysis}

Computational analysis of blood flow in the blood vessels was performed using the commercial finite element software ADINA Ver 8.5 (ADINA R \& D, Inc., Lebanon, Massachusetts, USA). Blood flow was assumed to be laminar, viscous, Newtonian, and incompressible because of its inherent flow characteristics. No-slip boundary conditions were assumed for the flow viscosity produced between the fluid and the wall surface of the blood vessels. Simulations were performed with the following material constants: blood density, $1100 \mathrm{~kg} / \mathrm{m}^{3}$, and blood dynamic viscosity, 0.004 Poiseuille. To achieve truly patient-specific modeling, the boundary conditions at the inflow boundary were based on the pulsatile periodic flow rate. Maximum wall shear stress (WSS) and flow velocities before and after stenting were obtained.

The velocity and flow rate of the internal carotid artery were obtained from gated phase contrast MR angiography in an age-matched male who did not have any intracranial vascular disease. The average velocities in the systolic and diastolic phases were $0.45 \mathrm{~m} / \mathrm{s}$ and $0.23 \mathrm{~m} / \mathrm{s}$, respectively.

\section{Patient Data}

A 65-year-old male patient who presented with right arm weakness revealed an acute focal cortical ischemic change in the borderzone type on the diffusionweighted image (not shown). He had diabetes mellitus and history of alcohol. He did not have arterial fibrillation or any coagulation disorders. Our Institutional Review Board approved this study, and we obtained written informed consent from the patient and the patient's family.

\section{RESULTS}

Cerebral angiogram after stenting showed no residual stenosis of the right M1 segment and the shift of borderzone between the anterior and the middle cerebral artery territory toward normal position $(5,6)$. Maximum WSS before and after stenting were shown in Figure $1 \mathrm{C}$ and D. Maximum WSSs before stenting were $18.5 \mathrm{~Pa}$ in systole and 9.3 $\mathrm{Pa}$ in end-diastole and those after stenting were 7.1 $\mathrm{Pa}$ in systole and 3.6 Pa. Maximum flow velocities before stenting were $135 \mathrm{~cm} / \mathrm{s}$ in systole and $70 \mathrm{~cm} / \mathrm{s}$ in diastole and those after stenting were 72 $\mathrm{cm} / \mathrm{s}$ in systole and $38 \mathrm{~cm} / \mathrm{s}$ in diastole.

Compared to previously reported process of CFD analysis, we could omit the several steps reduce the time spending in data processing $(11,12)$. Smoothing of vessel surface and trimming of branch vessels before CFD analysis required still considerable time to 


\section{Computational Flow Dynamics of the Severe M1 Stenosis Before and After Stenting}

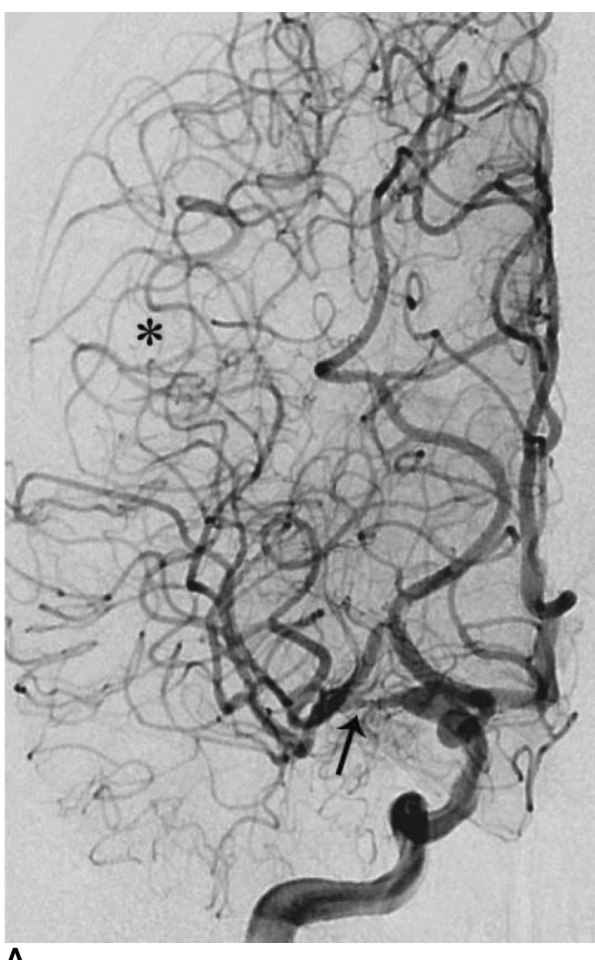

A

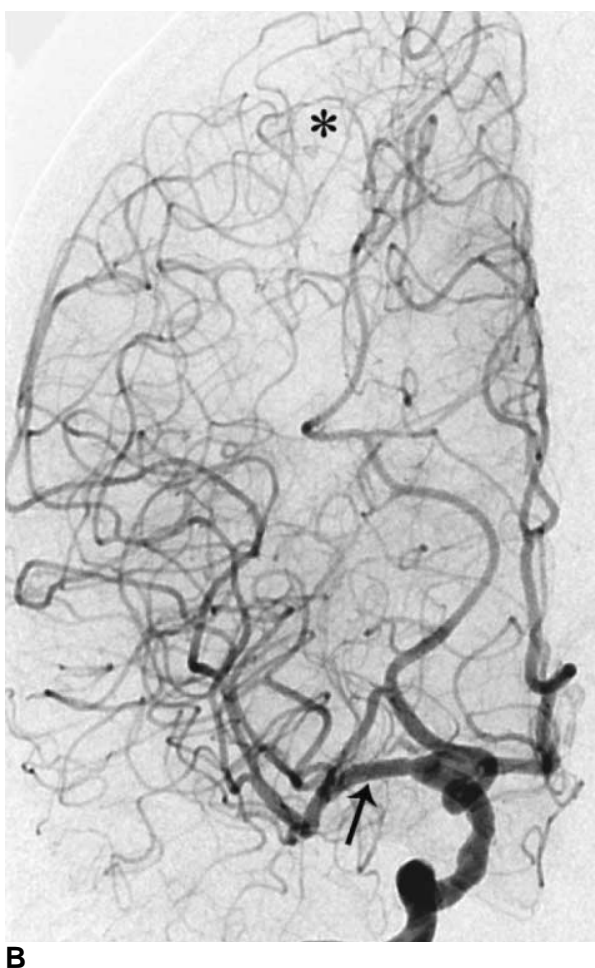

Fig. 1. Cerebral angiogram and Computational flow dynamics (CFD) study in the severe M1 stenosis. Angiograms before (A) and after (B) stenting show relieved severe stenosis of the right $\mathrm{M} 1$ and normalization of decreased size and filling of the right MCA branches after stenting (arrows in A \& B). Note upward shift of borderzone area to the upward normal postion after stenting (asterisk in $\mathbf{B}$ compared to $\mathbf{A}$ ).

C, D. Contour plot of the wall shear stress (WSS) map before stenting shows an increased WSS corresponding to the stenosis site during systole $(\mathbf{C})$ and end-diastole (D) (arrows).

E, F. Contour plot of the WSS map after stenting shows disappearance of high WSS area at normalized contour of the right M1suggesting hemodynamically successful stenting during systole (E) and end-diastole (F) (arrows).
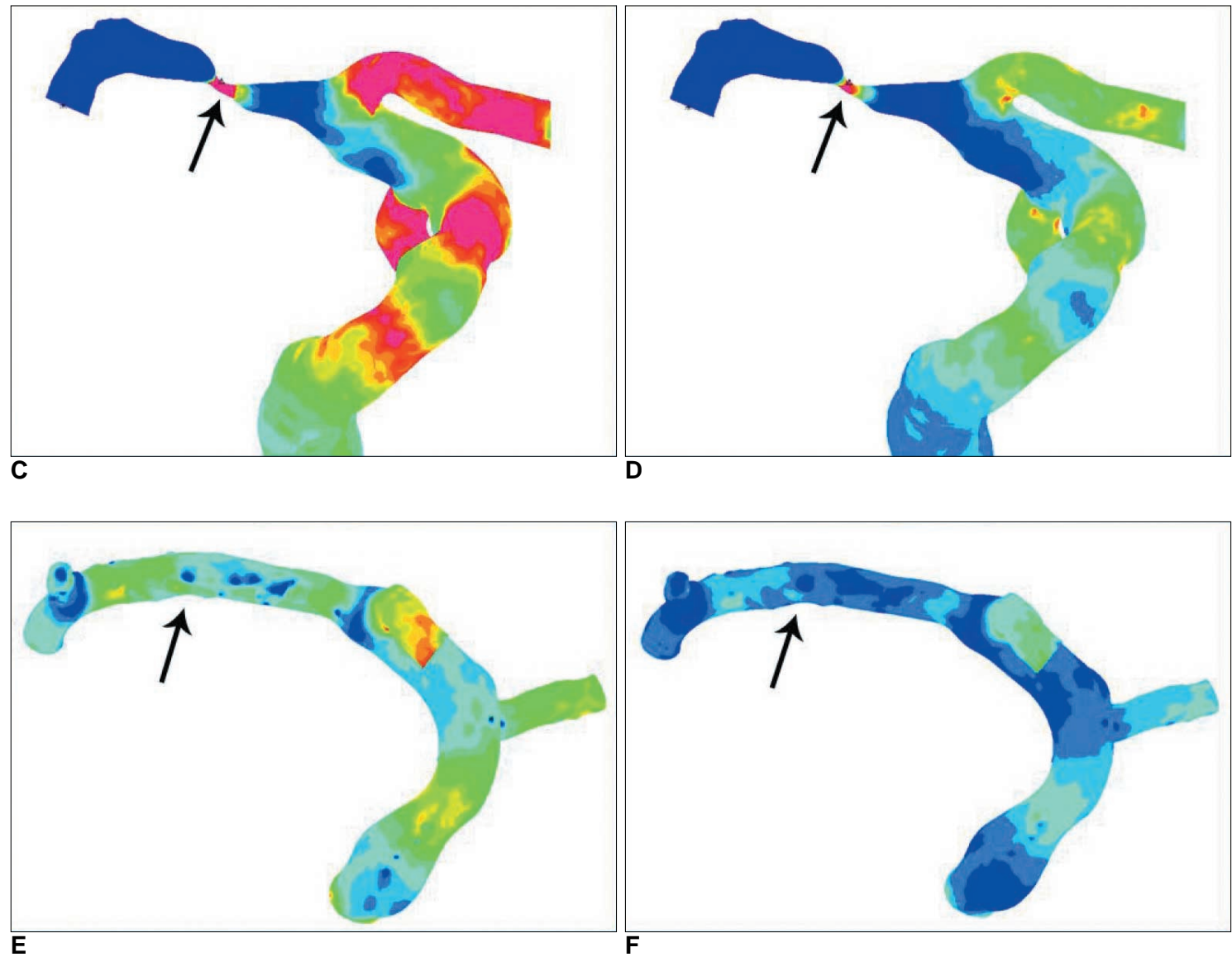


\section{Dae Chul Suh, et al.}

generate tetra volume mesh.

\section{DISCUSSION}

Since we demonstrated that CFD analysis of the smallcaliber intracranial artery was feasible and could be correlated with the atherosclerotic plaque in the stenotic segment, we obtained CFD before and after intracranial stenting and further simplified the process which could reduce analysis time $(11,12)$. Disappearance of WSS after stenting can be used as a beneficial landmark in assessing appropriate final luminal diameter preventing further angioplasty and even may predict minimal chance of restenosis at the hemodynamical point of view although follow-up study is mandatory to reach such a conclusion (12-14).

We found that the smoothing and trimming of branch vessels of the model vessel in Magic RP required a compromise. If we get high resolution image, it will takes time to generate too much tetra volume mesh. If we get low resolution image, processing time will be reduced but identification or differentiation of parent or branch vessels will be difficult (11).

Our study has several limitations. Firstly, image transfer from 3D angiogram to ADINA software was not yet possible and thus required a time-consuming tetra volume mesh generation even though we could reduce processing time since we used ADINA. If 3D angiogram is directly transferred to CFD analysis software such as ADINA, CFD analysis will be more readily applicable. Secondly, flow data in each patient was not readily provided for boundary condition in inflow as well as outflow zones of the model vessel $(11,15)$. Normal standard value of flow velocity according to age and gender groups might be helpful for the general usage. In addition, flow data from transcranial Doppler or MR phase study can be measured and used in each patient $(10,11)$.

In conclusions, we could reduce CFD processing time compared to previous report. We also demonstrated change of WSS, flow velocity and wall pressure in the severe stenotic intracranial artery, that is, M1 before and after stenting. This observation can provide a predictable risk factors affecting patient's outcome if the study can match to the long term followup data.

\section{Acknowledgements and Funding}

This study was supported by a grant from the Korea Healthcare Technology R\&D Project, Ministry of
Health \& Welfare, Republic of Korea. (A080201)

\section{References}

1. Suh DC, Lee SH, Kim KR, Park ST, Lim SM, Kim SJ, et al. Pattern of atherosclerotic carotid stenosis in Korean patients with stroke: different involvement of intracranial versus extracranial vessels. AJNR Am J Neuroradiol 2003;24:239-244

2. Gorelick PB, Caplan LR, Hier DB, Parker SL, Patel D. Racial differences in the distribution of anterior circulation occlusive disease. Neurology 1984;34:54-59

3. Sacco RL, Kargman DE, Gu Q, Zamanillo MC. Race-ethnicity and determinants of intracranial atherosclerotic cerebral infarction. The northern manhattan stroke study. Stroke 1995;26:14-20

4. Suh DC, Kim JK, Choi JW, Choi BS, Pyun HW, Choi YJ, et al. Intracranial stenting of severe symptomatic intracranial stenosis: results of 100 consecutive patients. AJNR Am J Neuroradiol 2008;29:781-785

5. Choi JW, Kim JK, Choi BS, Lim HK, Kim SJ, Kim JS, et al. Angiographic pattern of symptomatic severe M1 stenosis: comparison with presenting symptoms, infarct patterns, perfusion status, and outcome after recanalization. Cerebrovasc Dis 2010;29:297-303

6. Suh DC, Sung KB, Cho YS, Choi CG, Lee HK, Lee JH, et al. Transluminal angioplasty for middle cerebral artery stenosis in patients with acute ischemic stroke. AJNR Am J Neuroradiol 1999;20:553-558

7. Groen HC, Gijsen FJ, van der Lugt A, Ferguson MS, Hatsukami TS, van der Steen AF, et al. Plaque rupture in the carotid artery is localized at the high shear stress region: a case report. Stroke 2007;38:2379-2381

8. Malek AM, Alper SL, Izumo S. Hemodynamic shear stress and its role in atherosclerosis. JAMA 1999;282:2035-2042

9. Choi JW, Kim JK, Choi BS, Kim JH, Hwang HJ, Kim JS, et al. Adjuvant revascularization of intracranial artery occlusion with angioplasty and/or stenting. Neuroradiology 2009;51:33-43

10. Oh TS, Ko YB, Park ST, Yoon KH, Lee SW, Park JW, et al. Computational flow dynamics study in severe carotid bulb stenosis with ulceration. Neurointervention 2010;5:97-102

11. Suh DC, Park ST, Oh TS, Park SO, Lim OK, Park SC, et al. High shear stress in systolic phase at the surface of the enhancing plaque is related to symptom presentation of the severe M1 stenosis. Korean J Radiol 2011:[In press]

12. Garrett MC, Komotar RJ, Starke RM, Merkow MB, Otten ML, Sciacca RR, et al. The efficacy of direct extracranial-intracranial bypass in the treatment of symptomatic hemodynamic failure secondary to athero-occlusive disease: a systematic review. Clin Neurol Neurosurg 2009;111:319-326

13. He Y, Duraiswamy N, Frank AO, Moore JE. Blood flow in stented arteries: a parametric comparison of strut design patterns in three dimensions. J Biomech Eng 2005; 127:637-647

14. Murphy J, Boyle F. Predicting neointimal hyperplasia in stented arteries using time-dependant computational fluid dynamics: a review. Comput Biol Med 2010;40:408-418

15. Park ST, Kim JK, Yoon KH, Park SO, Park SW, Kim JS, et al. Atherosclerotic carotid stenoses of apical versus body lesions in high-risk carotid stenting patients. AJNR Am J Neuroradiol 2010;31:1106-1112 